\title{
New and Evolving Treatment Goals in Multiple Sclerosis - the Role of Teriflunomide
}

\author{
Patrick Vermersch \\ University of Lille, Lille, France
}

$\mathrm{T}$ eriflunomide is an oral immunotherapy agent that acts primarily as an inhibitor of dihydroorotate-dehydrogenase (DHODH), a key mitochondrial enzyme involved in the synthesis of pyrimidines in rapidly proliferating cells such as T lymphocytes and B lymphocytes, thus attenuating the inflammatory response to auto-antigens. The TEMSO and TOWER phase III clinical studies have demonstrated the efficacy and safety of teriflunomide in the first-line treatment of patients with relapsing multiple sclerosis (MS), with long-term follow-up data available up to 9 years. Teriflunomide has also been shown to decrease the risk of conversion to clinically definite MS (CDMS) in patients with a first clinical sign of MS or risk of conversion to CDMS after a clinically isolated syndrome. In addition to reducing disability progression and relapse rate, teriflunomide has also been found to decrease imaging activity and is associated with significant reductions in brain volume Ioss. The convenience of administration of teriflunomide should establish its role within the growing number of treatment options for MS.

\section{Keywords}

Teriflunomide, immunotherapy, multiple sclerosis

Disclosure: Patrick Vermersch has received honoraria and consulting fees from Biogen, Sanofi-Genzyme, Bayer, Novartis, Teva, Merck-Serono, Roche, Medday and Almirall. He has also received research support from Biogen, Bayer, Novartis, Sanofi-Genzyme, Roche and Merck-Serono. There were no publication fees associated with the publication of this article.

Compliance with Ethics: This study involves a review of the literature and did not involve any studies with human or animal subjects performed by any of the authors.

Acknowledgements: Medical writing support was provided by Katrina Mountfort, Freelance Writer, and was supported by Touch Medical Media.

Authorship: All named authors meet the International Committee of Medical Journal Editors (ICMJE) criteria for authorship of this manuscript, take responsibility for the integrity of the work as a whole, and have given final approval to the version to be published.

open Access: This article is published under the Creative Commons Attribution Noncommercial License, which permits any non-commercial use, distribution adaptation and reproduction provided the original author(s) and source are given appropriate credit.

Received: 1 February 2017

Accepted: 15 March 2017

Citation: European Neurological Review 2017;12(1):37-41

Corresponding Author: Patrick Vermersch, University of Lille, Department of Neurology,

Hôpital Roger Salengro, 59037 Lille Cedex,

France. E: patrick.vermersch@univ-lille2.fr
Multiple sclerosis (MS) is a chronic, progressive disease of the central nervous system (CNS), resulting from inflammatory lesions that become sites of demyelination and axonal injury. These lesions are associated with infiltrating T cells and monocytes, as well as B cells and plasma cells. ${ }^{1}$ Treatment of MS presents a challenge, since disease-modifying treatments (DMTs) must limit immune responses associated with disease initiation and propagation while also minimising any adverse effect on normal protective immune function. Enhanced understanding of the roles of T and B lymphocytes in the pathophysiology of relapsing MS have facilitated new approaches to managing MS with markedly improved efficacy. ${ }^{2,3}$ Treatment goals have changed: halting disability progression and promoting some degree of functional improvement are becoming achievable for many patients. ${ }^{3-5}$ The burden of treatment has also been decreased with the approval of a number of oral DMTs for relapsing-remitting MS (RRMS). ${ }^{6}$ Teriflunomide (Aubagio ${ }^{\circledR}$ Sanofi-Genzyme, Massachusetts, US) is an oral immunomodulatory agent that selectively targets T and B cells and has been approved both in the US and in Europe for the treatment of RRMS. ${ }^{7.8}$ This article will discuss the clinical evidence for the efficacy and safety of teriflunomide in MS, as well as clarifying the role of teriflunomide in the context of current and emerging MS treatment options.

\section{Teriflunomide in the treatment of multiple sclerosis}

Teriflunomide is the active metabolite of the parent drug, leflunomide, which has been in clinical use for many years as a treatment for rheumatoid arthritis. ${ }^{9}$ Following oral ingestion, leflunomide is rapidly converted almost entirely into teriflunomide. The latter has been found to have highly effective immunomodulatory and anti-inflammatory properties. ${ }^{7}$ Its precise effect of reducing $T$ and $B$ cells on the pathophysiology of MS has not been fully elucidated but is related to its action on the proliferation of activated lymphocytes. Teriflunomide selectively and reversibly inhibits the mitochondrial enzyme dihydroorotate dehydrogenase in de novo pyrimidine synthesis, halting cell division in cells such as autoreactive T- and B-lymphocytes in MS and limiting their involvement in the inflammatory processes underlying MS. ${ }^{10-15}$ Mean reductions of white blood cell counts of around 15\% occur during the first 6 weeks of teriflunomide initiation and persist during treatment, although mean absolute counts remain within the normal range for most patients. ${ }^{18} \mathrm{~A}$ similar reduction has been reported for dimethyl fumarate (DMF). ${ }^{16}$ Cells that do not proliferate in response to activation, e.g. resting lymphocytes, can divide through homeostatic proliferation in which pyrimidines are synthesised by means of the salvage pathway. ${ }^{10,11}$ As a result of teriflunomide action, fewer autoreactive T- and B-lymphocytes cross the bloodbrain barrier into the CNS but there is no apparent effect on the viability of stimulated T or B cells, a limited impact on lymphocyte activation and no direct effects on DNA. ${ }^{10,7,18}$

The impact of teriflunomide on adaptive immune cell subsets in humans was recently demonstrated in the TERI-DYNAMIC study: ${ }^{19}$ patients $(n=39)$ with RRMS received teriflunomide $14 \mathrm{mg}$ once daily for 24 weeks. From baseline to week 12 and week 24, the proportion of CD19+ 
Table 1: The TEMSO and TOWER trials - baseline characteristics

\begin{tabular}{|c|c|c|}
\hline & TEMSO ${ }^{20}$ & TOWER $^{21}$ \\
\hline Study design & \multicolumn{2}{|c|}{$\begin{array}{l}\text { Multicentre, multinational, randomised, double-blind, } \\
\text { parallel-arm, placebo-controlled }\end{array}$} \\
\hline $\begin{array}{l}\text { Patients } \\
\text { (randomised), n }\end{array}$ & 1,088 & 1,169 \\
\hline Study duration & 108 wk & $\begin{array}{l}\text { Ended } 48 \text { wk after last patient } \\
\text { randomised (mean exposure, } \\
82 \text { wk, max } 152 \text { wk) }\end{array}$ \\
\hline $\begin{array}{l}\text { Patient } \\
\text { population }\end{array}$ & \multicolumn{2}{|c|}{$\begin{array}{c}\text { Patients with RMS (McDonald } 2001 \text { criteria }^{22,23} \text { ) } \\
\text { Aged } 18-55 \text { years } \\
\text { EDSS score } \leq 5.5 \text { at screening } \\
\geq 2 \text { relapses within } 2 \text { years or } \geq 1 \text { relapse within } 1 \text { year } \\
\text { before randomisation }\end{array}$} \\
\hline Treatment arms & \multicolumn{2}{|c|}{$\begin{array}{l}\text { Once-daily, oral }(1: 1: 1 \text { ratio) } \\
\text { Teriflunomide } 14 \mathrm{mg}: \text { Teriflunomide } 7 \mathrm{mg} \text { : Placebo }\end{array}$} \\
\hline Primary outcome & \multicolumn{2}{|c|}{ ARR (number of relapses per patient-year) } \\
\hline $\begin{array}{l}\text { Secondary } \\
\text { outcomes }\end{array}$ & $\begin{array}{l}\text { Key: Time to } 12 \text {-wk sustained } \\
\text { accumulation of disability } \\
\text { MRI measures, safety }\end{array}$ & $\begin{array}{l}\text { Key: Time to 12-wk sustained } \\
\text { accumulation of disability } \\
\text { Safety }\end{array}$ \\
\hline
\end{tabular}

$A R R=$ annualised relapse rate; $E D S S=$ Expanded Disability Status Scale;

$M R I=$ magnetic resonance imaging $: R M S=$ relapsing multiple sclerosis:

TEMSO = Teriflunomide Multiple Sclerosis Oral; TOWER = Teriflunomide in Patients

With Relapsing Multiple Sclerosis; wk = week; Data sourced from: Genzyme, 2014,

O'Connor et al., 2011, ${ }^{20}$ Confavreux et al., 2014, ${ }^{21}$ Polman et al., 2005, ${ }^{23}$

B cells and absolute counts of Th1 cells decreased and the proportion of $\mathrm{CD} 4+$ cells versus CD8+ cytotoxic cells increased. Results also showed that teriflunomide decreases clonal diversity, which provides an immunomodulatory action without impairing immune function. ${ }^{19}$

\section{Clinical evidence for the efficacy of teriflunomide}

Two multicentre, multinational, randomised double-blind parallel-arm, placebo-controlled studies, TEMSO ${ }^{20}$ and TOWER, ${ }^{21}$ have examined the efficacy and safety of teriflunomide $14 \mathrm{mg}$ and $7 \mathrm{mg}$ /day in patients with MS. The study designs and baseline characteristics were similar in both trials; patients had relapsing MS, were between the ages of 18 and 55 years old, had Expanded Disability Status Scale (EDSS) scores $\leq 5.5$, and at least two clinical relapses in the preceding 2 years, or at least one relapse in the previous year. Patients were randomised to teriflunomide $14 \mathrm{mg}$ or $7 \mathrm{mg} /$ day or placebo once daily for 108 weeks (Table 1). In the TEMSO and TOWER studies, compared with placebo, teriflunomide reduced the annualised relapse rate (ARR) relative risk by $32 \%(p<0.001)$ and $36 \%$ ( $p=0.0001)$, for $14 \mathrm{mg}$ and $7 \mathrm{mg}$ respectively. Results showed $29.8 \%(p=0.028)$ and $31.5 \%(p=0.044)$ relative risk reductions for $14 \mathrm{mg}$ teriflunomide versus placebo for confirmed disability progression in the TEMSO and TOWER studies, respectively (Figure 1). ${ }^{20,21}$ In the TEMSO study, teriflunomide $14 \mathrm{mg}$ treatment resulted in a $67.4 \%$ relative reduction in new 2 lesion volume $(p<0.001)^{20.24}$ and an $80.4 \%$ reduction in the number of gadolinium (Gd)-enhancing T1 lesions per scan at week 108. ${ }^{24}$

Recently, long-term data from TEMSO has been released: no new or unexpected adverse events (AES) occurred in patients receiving teriflunomide for up to 9 years. Disease activity decreased in patients switching from placebo and remained low in patients continuing on teriflunomide..$^{25}$

In the TOWER study extension, the improvement in disability progression has been sustained up to 5.5 years. A mean change in EDSS from baseline
Figure 1: Confirmed disability progression during teriflunomide or placebo treatment in the TEMSO and TOWER studies

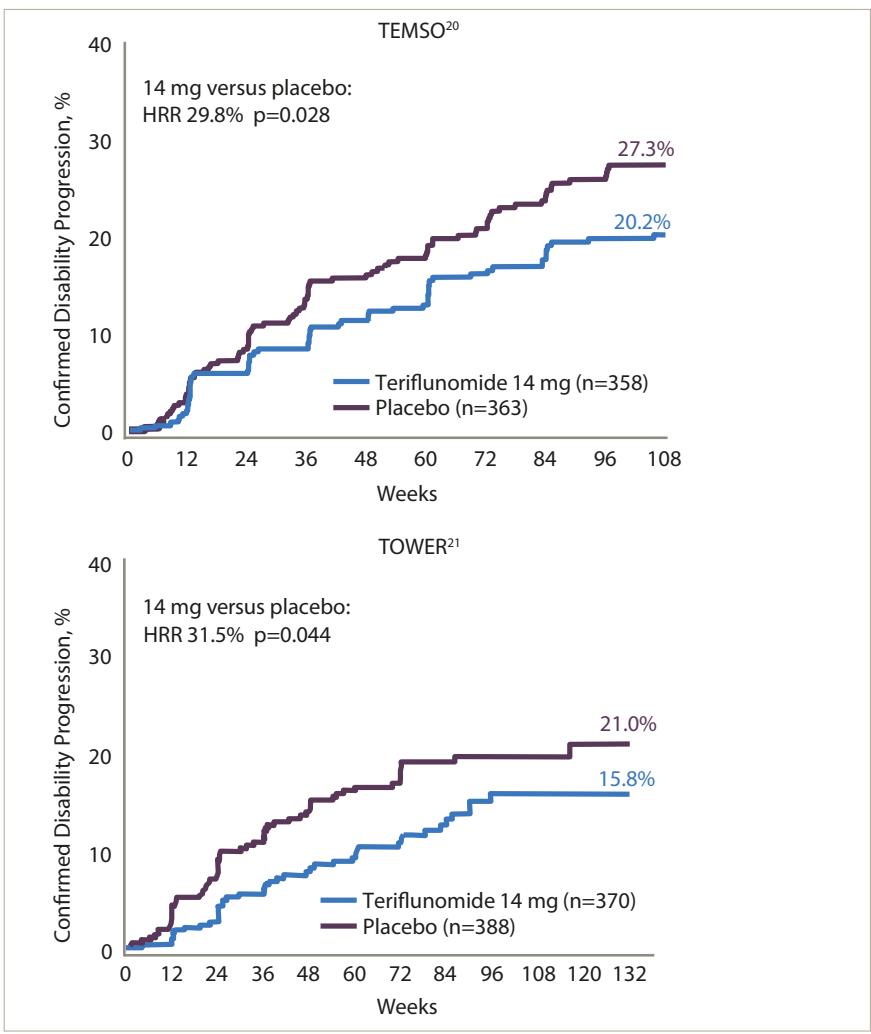

HRR = hazard ratio reduction: TEMSO = Teriflunomide Multiple Sclerosis Oral: TOWER = Teriflunomide in Patients With Relapsing Multiple Sclerosis. Data sourced from: Genzyme, 2014, ${ }^{7}$ O'Connor et al., $2011^{20}$ and Confavreux et al., 2014. ${ }^{21}$

of $<0.15$ points ${ }^{26}$ and the median EDSS was in the range 2.0-2.5 at all time points. ${ }^{27}$ Similar control of disability progression has also been observed in the TEMSO long-term extension study. ${ }^{28}$

A post-hoc analysis of pooled data from both the TEMSO and TOWER studies showed that ARR was reduced by $33.7 \%$ with teriflunomide $14 \mathrm{mg}$ versus placebo $(p<0.0001)$ and by $27.0 \%$ with teriflunomide $7 \mathrm{mg}$ versus placebo $(p<0.0001)$. Confirmed disability progression was reduced by $30.5 \%$ with teriflunomide $14 \mathrm{mg}$ ( $\mathrm{p}=0.0029$ versus placebo). However, teriflunomide $7 \mathrm{mg}$ did not show a significant effect on disability progression. ${ }^{29}$

Teriflunomide has also been investigated in MS at different disease stages. The TOPIC study was a phase III clinical trial that evaluated the efficacy of teriflunomide in preventing conversion to clinically definite MS (CDMS) in patients with first demyelinating events suggestive of MS. ${ }^{30}$ Patients $(n=618)$ with clinically isolated syndrome (defined as a neurological event consistent with demyelination, starting within 90 days of randomisation, and two or more T2-weighted magnetic resonance imaging (MRI) lesions $\geq 3 \mathrm{~mm}$ in diameter) were randomised to once-daily oral teriflunomide $14 \mathrm{mg}$, teriflunomide $7 \mathrm{mg}$, or placebo. At 108 weeks, teriflunomide (14 mg) decreased the risk of conversion to CDMS by $42.6 \%$ versus placebo $(p=0.0087)$, as well reduced the risk of another relapse or new MRI lesion by $34.9 \%(p=0.0003)$ compared with placebo. ${ }^{30}$ Teriflunomide $14 \mathrm{mg}$ reduced risk in the number and volume of $\mathrm{Gd}$-enhancing lesions by $58.5 \%$ ( $p=0.0008$ ). Teriflunomide $7 \mathrm{mg}$ decreased conversion to CDMS by $37.2 \%$ versus placebo $(\mathrm{p}=0.0271$ ) and the risk of recurrent relapse or new MRI lesion formation by $31.4 \%$ versus placebo $(p=0.0020)$, and reduced the number but not the volume of Gd-enhancing lesions..$^{30}$ 
Table 2: Overview of safety of teriflunomide across the clinical development programme

\begin{tabular}{|c|c|c|}
\hline \multicolumn{3}{|c|}{ Pooled safety from phase III, TOPIC, TEMSO and TOWER } \\
\hline$n(\%)$ & $\begin{array}{l}\text { Placebo } \\
(n=997)\end{array}$ & $\begin{array}{l}\text { Teriflunomide } \\
14 \mathrm{mg}(\mathrm{n}=1,002)\end{array}$ \\
\hline All AES & $853(85.6)$ & 885 (88.3) \\
\hline SAES & $119(11.9)$ & $133(13.3)$ \\
\hline AEs leading to discontinuation & $75(7.5)$ & $125(12.5)$ \\
\hline \multicolumn{3}{|l|}{ Intensity } \\
\hline Mild & $285(33.4)$ & $281(31.8)$ \\
\hline Moderate & $448(52.5)$ & $477(53.9)$ \\
\hline Severe & $120(14.1)$ & $127(14.4)$ \\
\hline
\end{tabular}

AES = adverse events; $S A E S$ = severe adverse events; TEMSO = Teriflunomide Multiple Sclerosis Oral; TOPIC = Teriflunomide Versus Placebo in Patients With First Clinical Symptom of Multiple Sclerosis; TOWER = Teriflunomide in Patients With Relapsing Multiple Sclerosis. Data sourced from: Comi et al., 2016, ${ }^{41}$ Leist, et al., 2015, ${ }^{42}$ Kremenchutzky et al., 2015.4

To gain a better understanding of the clinical implications of the results of the phase III pivotal teriflunomide studies, compared with those of other disease-modifying therapies (DMTs) pivotal phase III trials, it is useful to calculate the number needed to treat (NNT) to benefit one patient. ${ }^{31}$ This takes into account not only the treatment effect, but also the rarity of the event in question (e.g., relapse); thus, a higher NNT would be expected if fewer patients experienced the event in the time period of interest. There has been a downward trend in MS relapse rates over the past decade, making it difficult to compare studies conducted at different times. A post-hoc analysis found that the absolute ARR reductions for TEMSO and TOWER were -0.17 and -0.18 , and NNTs were 5.9 and 5.6 , respectively. ${ }^{32}$ This was similar to findings of the two pivotal studies of DMF $240 \mathrm{mg}$ (DEFINE ${ }^{33}$ [Determination of the Efficacy and Safety of Oral Fumarate in Relapsing-Remitting Multiple Sclerosis] and CONFIRM $^{34}$ [Comparator and an Oral Fumarate in Relapsing-Remitting Multiple Sclerosis]) in which the relapse rates were also significantly reduced versus placebo. The absolute ARR reductions for DEFINE and CONFIRM were -0.19 and -0.18 and NNTs were 5.3 and 5.6 , respectively. This similarity in NNTS was observed despite a higher relative relapse risk reduction for DMF compared with teriflunomide. ${ }^{35}$ In the TEMSO, TOWER, DEFINE and CONFIRM studies, the NNTS for prevention of disease progression were $13.8,17.4,10.8$, and 30.2 , respectively. These data suggest a potentially greater treatment effect of teriflunomide. However, it should be noted that there was a low number of relapses in the DMF studies, which may confound this comparison. In an analysis of pivotal studies of DMF, fingolimod and teriflunomide, NNTS to prevent any relapse, more severe relapses (such as those leading to hospitalisation or requiring intravenous corticosteroids), and disability worsening. were similar for DMF and teriflunomide, and marginally lower for fingolimod. ${ }^{32}$

Another post-hoc analysis of TEMSO found that teriflunomide reduced relapses leading to hospitalisation (by $36 \%$ in the $7 \mathrm{mg}$ group [ $\mathrm{p}=0.015]$ and $59 \%$ in the $14 \mathrm{mg}$ group $[\mathrm{p}<0.0001]$ ) and intravenous corticosteroid use versus placebo (29\% [ $p=0.001] ; 34 \%$ [p=0.0003]) and also that teriflunomide-treated patients spent fewer nights in hospital for relapses $(p<0.01)$. In addition, teriflunomide reduced the annualised rate of all hospitalisations $(p=0.01)$ and emergency room visits $(p=0.004)$. This may translate to reduced healthcare costs. ${ }^{36}$

A further demonstration of teriflunomide efficacy was the achievement of no evidence disease activity (NEDA) status during the core phase of
Figure 2: Annualized brain volume loss over 2 years during treatment with teriflunomide or placebo in the TEMSO study

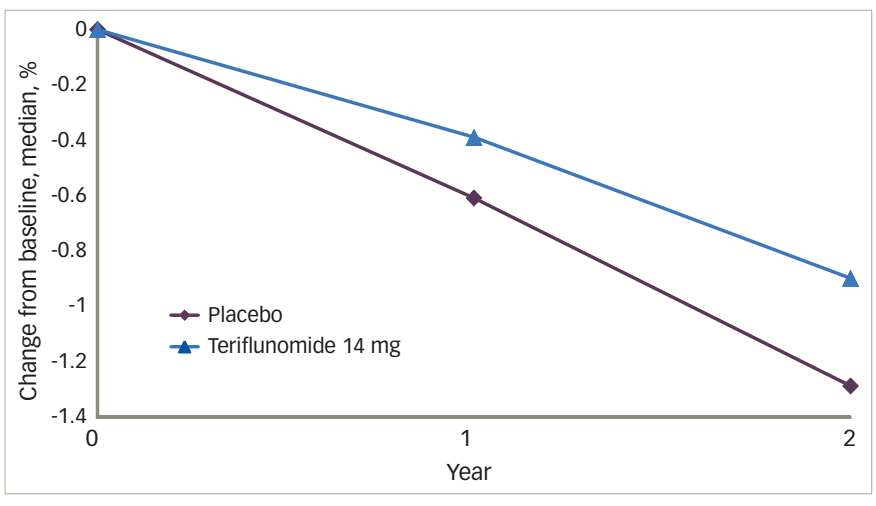

TEMSO = Teriflunomide Multiple Sclerosis Oral. Reproduced under the CC-BY-NC-ND license from: Radue et al., 2015.39

the TEMSO study. ${ }^{37}$ NEDA was defined as no Gd-enhancing T1 lesions or new/enlarging T2 lesions, and no clinical relapse or 12-week sustained disability progression. In Year 1 significantly more patients receiving teriflunomide achieved NEDA than those receiving placebo $33.1 \%$ versus $19.4 \%, p<0.0001)$. In Year 2 this difference was maintained (35.3\% and $21.2 \%$, respectively, $p=0.0002){ }^{37}$ These data support the continued efficacy benefits of ongoing treatment with teriflunomide.

While clinical measures of efficacy are essential, patient-reported outcomes are also important in establishing the usefulness of a drug in routine clinical practice. The improvement in disability from the patients' perspective has been investigated in the phase IV, single-arm, open-label TeriPRO study $(n=1,001){ }^{38}$ Patients receiving teriflunomide indicated disability level during the past month in eight domains of the Multiple Sclerosis Performance Scales (MSPS). In a 6-month, interim analysis, $52.8 \%$ reported an improvement, $10.2 \%$ reported no change and $37.0 \%$ reported worsening. There were improvements reported for domains of mobility, hand function and vision. A 6-month interim analysis showed that at baseline $41.3 \%$ of patients reported normal/minimal disability due to cognitive symptoms; after 6 months of teriflunomide treatment this had increased to $48.1 \%$. In patients switching from another DMT within 6 months of enrolment, mean TSQM (Treatment Satisfaction Questionnaire for Medication) Global Satisfaction score was 74.9, a 22.7point improvement compared with baseline. ${ }^{38}$

\section{Effect of teriflunomide on brain volume}

There is increasing interest in brain volume (BV) atrophy and its effects on disability in MS, largely due to wider adoption of protocols that specify its measurement. In the MRI investigations of the TEMSO study, an analysis using the SIENA (Structural Image Evaluation using Normalization of Atrophy) protocol revealed significant treatment effects. ${ }^{39}$ With teriflunomide $14 \mathrm{mg}$, there was a 39.6\% reduction in BV loss after 1 year $(p<0.0001)$ and $30.6 \%$ reduction after 2 years $(p<0.0001)$ versus placebo (Figure 2). Median BV was reduced by $0.39 \%$ with teriflunomide and $0.61 \%$ with placebo after 1 year and by $0.90 \%$ and $1.29 \%$ after 2 years $(p=0.0001$ for both comparisons). These findings using an established measure of brain tissue loss, are consistent with the effects of teriflunomide on delaying disability progression.

\section{Safety findings of studies of teriflunomide}

The safety profile of teriflunomide is based on a population of over 5,000 patients, mostly with RRMS. ${ }^{27}$ A pooled analysis of TEMSO, TOWER, and 
Figure 3: Mean neutrophil and lymphocyte counts in a pooled analysis of data from the TEMSO, TOWER and TOPIC studies
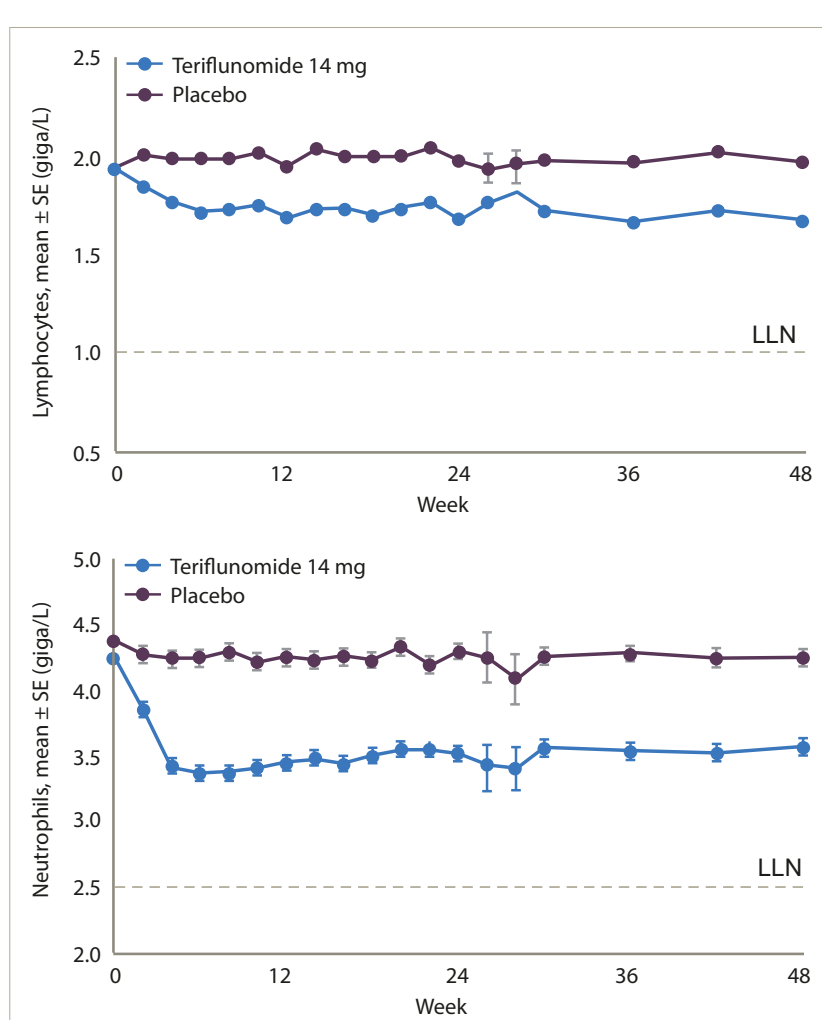

$L L N=$ lower limit of normal; SE = standard error; TEMSO = Teriflunomide Multiple Sclerosis Oral; TOPIC = Teriflunomide Versus Placebo in Patients With First Clinical Symptom of Multiple Sclerosis; TOWER = Teriflunomide in Patients With Relapsing Multiple Sclerosis. Reproduced with permissions from Comi et al., 2014. ${ }^{40}$

TOPIC study data investigated the effect of teriflunomide on lymphocyte and neutrophil counts..$^{40}$ The mean lymphocyte and neutrophil counts decreased during the first 6 or 12 weeks of treatment versus placebo. After the initial treatment period, levels remained stable (Figure 3) and were well above the lower limit of normal, suggesting preserved immune function. Neutrophil and lymphocyte count decreases were mostly mild to moderate (Grade 1-2). ${ }^{41}$ There was no association between infection and decreased lymphocyte counts in all three clinical studies.

Infection rates were similar for patients receiving teriflunomide $14 \mathrm{mg}$ versus placebo $(52.7 \%$ versus $53.4 \%$ for any infection and $2.7 \%$ versus $2.2 \%$ for any serious infection). ${ }^{14,42}$ Two serious opportunistic infections occurred in the teriflunomide $14 \mathrm{mg}$ group. ${ }^{43}$ One patient experienced gastrointestinal tuberculosis, leading to permanent discontinuation of treatment. Another patient developed hepatitis with cytomegalovirus infection, again leading to treatment discontinuation. Two patients died as a result of infections: one was in the placebo group (respiratory tract infection) and one in the teriflunomide $14 \mathrm{mg}$ group (gram-negative bacterial sepsis). ${ }^{43}$

The overall incidence of AES was similar for teriflunomide $14 \mathrm{mg}$ and placebo (Table 2). ${ }^{41,42}$ The frequencies of all AEs for teriflunomide and placebo were $88.3 \%$ and $85.6 \%$, respectively. Serious AEs were reported in $13.3 \%$ and $11.9 \%$, respectively. The distribution of mild, moderate and severe AEs was also similar between teriflunomide and placebo. The most common AEs reported with teriflunomide were: hair thinning, diarrhoea, alanine aminotransferase (ALT) increase, nausea, and headache; the majority resolved on treatment. A low incidence of malignancy $(\leq 0.4 \%)$ was observed in all treatment groups, with no unusual pattern of malignancy, including haematological malignancies and lymphoproliferative tumours. ${ }^{41}$ The most common reason for treatment discontinuation in all treatment groups was ALT elevation, reflecting the labelling indication to discontinue treatment on confirmation of ALT >3-times the upper limit of normal (ULN). The proportion of patients with hepatic disorders was higher in the teriflunomide groups (14 mg, 21.5\%; 7 mg, 19.8\%; placebo, 15.2\%), largely due to transient and reversible ALT increases $\leq 3$-times the ULN. ${ }^{41}$ Follow-up for 12 years in the phase II study showed the types of AES were similar to those of the placebo-controlled studies. ${ }^{44}$

Preservation of protective immunity after teriflunomide has been addressed by the TERIVA (teriflunomide and vaccination) study, which investigated the effects of influenza vaccination patients with RRMS. ${ }^{45}$ At 28 days post vaccination, the proportions treated with $14 \mathrm{mg}$ teriflunomide who had $\mathrm{a} \geq 40$ titre to influenza antigens $\mathrm{H} 1 \mathrm{~N} 1, \mathrm{H} 2 \mathrm{~N} 3$ and B were: $97.4 \%$, $76.9 \%$ and $97.4 \%$, respectively. These proportions in patients treated with IFN $\beta$-1a were $97.7 \%, 90.7 \%$ and $93.0 \%$, respectively. These responses were all above the European Medicines Agency (EMA)-defined threshold for efficacy of influenza vaccination in 18- to 60 -year-olds. ${ }^{46}$

No signals for teratogenicity have been reported in the teriflunomide clinical trial database. In a 2014 report, no structural or functional deficits had been reported in 83 patients who had taken teriflunomide during pregnancies leading to live births and 22 pregnancies in partners of male patients. ${ }^{47}$ Median birth weight, for 18 newborns, was $3.3 \mathrm{~kg}$, and mean gestational age, documented in 23 cases, was 39 weeks (range 36-44 weeks). All newborns were healthy and did not have any structural or functional abnormalities at birth. The spontaneous abortion rate in teriflunomide-exposed patients was $18.6 \%,{ }^{47}$ within the range reported for the general population. ${ }^{48}$

In a further study on healthy human subjects $(n=46)$, teriflunomide produced no notable impact on immune response to recall antigens (Candida albicans, Trichophyton, and tuberculin) or neoantigens (rabies vaccine) versus placebo ${ }^{49}$

\section{Discussion and Conclusion}

Continuing advances in the management of MS have markedly raised the bar in treatment goals in recent years. It is now possible to stabilise disability progression and even reverse it. Selective targeting of T and $\mathrm{B}$ cells has proven to be a successful strategy in MS treatment. The oral treatment, teriflunomide, can be used as a first-line therapy in MS. This drug depletes autoreactive T and B cells but does not eliminate precursor or non-autoreactive cells. Decreased inflammation in neuronal tissue is accompanied by normal immune function allowing continued immune responses to infection and vaccination.

The selective action of teriflunomide is reflected in efficacy and safety findings from up to 12-years in a clinical development programme involving over 5,000 patients that showed effective control of MS symptoms and progression, and the risk of infection was little different to either placebo or a comparator treatment interferon beta-1a (IFN $\beta$ 1a). Teriflunomide treatment has yielded significant reductions in BV Ioss compared with placebo or comparator in the TEMSO study. Interim analyses show improvements in cognition and studies are ongoing to further explore this effect.

The role of teriflunomide among the growing number of treatment options for MS is unclear. In the absence of head-to-head trials, its efficacy relative to other first-line parenteral agents is unknown, but phase III clinical trial 
data suggest its efficacy is similar to existing injected agents. Its efficacy appears to be lower than that of other oral agents such as fingolimod but its ease of use and favourable safety profile compared to fingolimod make it an attractive treatment option. However, the convenience of oral administration, as well as safety and tolerability, should lead to more widespread use. The use of an oral drug such as teriflunomide may improve adherence and reduce lifestyle restrictions associated with injected therapies. Further studies are needed to determine the optimum sequence of administering teriflunomide and existing therapies and whether it can be used in combination with other agents. There is also a need to identify the ideal responder profile to teriflunomide. Individual genetic or clinical features might predict an optimal response to teriflunomide for a patient at particular stage of the disease. The mechanism of action of teriflunomide suggests that it may be most effective between the early and the relapsing-remitting stage of MS, when immune and inflammatory processes need to be controlled.11

In conclusion, there is a need for further clinical data as well as postmarketing studies to fully define the role of teriflunomide among the MS treatment armamentarium. $\square$
1. McFarland HF, Martin R, Multiple sclerosis: a complicated picture of autoimmunity, Nat Immunol, 2007:8:913-9.

2. Oh J, O'Connor PW, Novel and imminently emerging treatments in relapsing-remitting multiple sclerosis, Curr Opin Neurol, 2015;28:230-6.

3. Sorensen PS, New management algorithms in multiple sclerosis, Curr Opin Neurol, 2014:27:246-59.

4. Feinstein A, Freeman J, Lo AC, Treatment of progressive multiple sclerosis: what works, what does not, and what is needed, Lancet Neurol, 2015;14:194-207.

5. FoX EJ, Rhoades RW, New treatments and treatment goals fo patients with relapsing-remitting multiple sclerosis, Curr Opi Neurol, 2012;25 Suppl:S11-9.

6. Marriott JJ, O'Connor PW, Emerging therapies in relapsingremitting multiple sclerosis, Rev Recent Clin Trials, 2010;5:179-88.

7. Genzyme Therapeutics, Aubagio, Summary of Product Characteristics. Available at: www.medicines.org.uk/emc medicine/28533 (accessed 14 March 2017).

8. Genzyme Corporation. US Prescribing Information. Available at: http://products.sanofi.us/aubagio/aubagio.pdf (accessed 14 March 2017).

9. Osiri M, Shea B, Robinson V, et al., Leflunomide for treating rheumatoid arthritis, Cochrane Database Syst Rev , 2003; CD002047

10. Bar-Or A, Pachner A, Menguy-Vacheron F, et al., Teriflunomide and its mechanism of action in multiple sclerosis, Drugs, 2014;74:659-74.

11. Genc K, Dona DL, Reder AT, Increased CD80(+) B cells in active multiple sclerosis and reversal by interferon beta- $1 \mathrm{~b}$ therapy, J Clin Invest, 1997;99:2664-71.

12. Gold R, Wolinsky JS, Pathophysiology of multiple sclerosis and the place of teriflunomide, Acta Neurol Scand, 2011;124:75-84.

13. Rawls J, Knecht W, Diekert K, et al., Requirements for the mitochondrial import and localization of dihydroorotate dehydrogenase, Eur J Biochem, 2000;267:2079-87.

14. Warnke C, Meyer zu Horste G, Hartung HP, et al, Review of teriflunomide and its potential in the treatment of multiple sclerosis, Neuropsychiatr Dis Treat, 2009;5:333-40.

15. Knecht W, Bergjohann U, Gonski S, et al., Functional expression of a fragment of human dihydroorotate dehydrogenase by means of the baculovirus expression vector system, and kinetic investigation of the purified recombinant enzyme, Eur J Biochem, 1996;240:292-301.

16. Gold R, Kappos L, Arnold DL, et al., Placebo-controlled phase 3 study of oral BG-12 for relapsing multiple sclerosis, N Eng/ Med, 2012;367:1098-107.

17. Kaplan J, Cavalier S, Turpault S, Biodistribution of teriflunomide in naive rats vs rats with experimental autoimmune encephalomyelitis, Presented at: 31 st Congress of the encephal European Commitee for Research in Multiple Sclerosis

18. Li L LiU J, Delohey T, et al., The effects of teiflunomide on

8. LI L, Liu J, Belohery T, et al., the effects of teriflunomide on lymphocyte subpopulations in human peripheral blood mononuclear cells in vitro, J Neuroimmunol, 2013;265:82-90.

19. Wiendl $\mathrm{H}$, Gross $\mathrm{C}$, Lindman M, et al., TERI-DYNAMIC: exploring the impact of teriflunomide on immune cell population size, receptor repertoire, and function in patients with RRMS, Neurology, 2016;86:Suppl. P5.282.
20. O'Connor P, Wolinsky JS, Confavreux C, et al., Randomized trial of oral teriflunomide for relapsing multiple sclerosis, N Eng/ 」 Med, 2011;365:1293-303

21. Confavreux $\mathrm{C}, \mathrm{O}^{\prime}$ Connor $\mathrm{P}$, Comi $\mathrm{G}$, et al., Oral teriflunomide for patients with relapsing multiple sclerosis (TOWER): a randomised, double-blind, placebo-controlled, phase 3 trial, randomised, double-blind, place

22. McDonald WI Compston A, Edan $G$, et al., Recommended diagnostic criteria for multiple sclerosis: guidelines from the International Panel on the diagnosis of multiple sclerosis, Ann Neurol, 2001;50:121-7.

23. Polman $\mathrm{CH}$, Reingold SC, Edan G, et al., Diagnostic criteria for multiple sclerosis: 2005 revisions to the "McDonald Criteria", Ann Neurol, 2005;58:840-6.

24. Wolinsky JS, Narayana PA, Nelson F, et al., Magnetic resonance imaging outcomes from a phase III trial of teriflunomide, Mult Scler, 2013;19:1310-9.

25. O'Connor P, Comi G, Freedman MS, et al., Long-term safety and efficacy of teriflunomide: Nine-year follow-up of the randomized TEMSO study Neurology, 2016:86:920-30.

26. Kappos LF, Freedman MS, Comi G, et al., Teriflunomide efficacy on annualized relapse rate and expanded disability status scale scores: 2.5-year follow-up in the TOWER extension study in patients with relapsing MS, Presented at: 31 st Congress of the European Committee for Research in Multiple Sclerosis (ECTRIMS), Barcelona, Spain, 7-10 October 2015, P1099.

27. Genzyme - a Sanofi company, Cambridge, Massachusetts, United States. Data on file, 2015

28. Freedman MS, Wollinsky J, Comi G, et al., Safety and efficacy of teriflunomide for up to 9 Years in relapsing forms of multiple sclerosis: update of the TEMSO extension trial, Neurology, 2014;82:Supplement P3.150

29. Kappos L, Pooled efficacy data from two phase 3 placebocontrolled trials of oral, once-daily teriflunomide, Abstract 34098. Presented at: Congress of the Europenn Committee for Treatment and Research in Multiple Sclerosis (ECTRIMS) Copenhagen, Denmark, 2-5 October, 2013.

30. Miller AE, Wolinsky JS, Kappos L, et al., Oral teriflunomide for patients with a first clinical episode suggestive of multiple sclerosis (TOPIC): a randomised, double-blind, placebo-controlled, phase 3 trial, Lancet Neurol, 2014;13:977-86.

31. Cook RJ, Sackett DL, The number needed to treat: a clinically useful measure of treatment effect, BMJ, 1995;310:452-4.

32. Freedman MS, Montalban X, Miller AE, et al., Comparing outcomes from clinical studies of oral disease-modifying therapies (dimethyl fumarate, fingolimod, and teriflunomide) in relapsing MS: Assessing absolute differences using a number needed to treat analysis, Mult Scler Relat Disord, 2016;10:204-12.

33. Gold R, Kappos L, Arnold DL, et al., Placebo-controlled phase 3 study of oral BG-12 for relapsing multiple sclerosis, N Eng/ J Med, 2012:367:1098-107.

34. Fox RJ, Miller DH, Phillips JT, et al., Placebo-controlled phase 3 study of oral BG-12 or glatiramer in multiple sclerosis, N Eng/ Med, 2012:367:1087-97.

35. Leist T, Freedman M, Miller A, et al., Assessing comparative outcomes from teriflunomide and dimethyl fumarate studies in relapsing MS: use of "number needed to treat" analysis, Neurology, 84:Suppl. P3.245.
36. O'Connor PW, Lublin FD, Wolinsky JS, et al., Teriflunomide reduces relapse-related neurological sequelae, hospitalizations and steroid use, I Neurol, 2013;260:2472-80.

37. Wolinsky JS, Freedman MS, Thangavelu K, et al., Efficacy of teriflunomide treatment in achieving no evidence of disease teriflunomide treatment in achieving no evidence of disease at: 31st Congress of the European committee for Research in Mutsiple Sclerosis (ECTRIMS), Barcelona, Spain, 7-10 October Multiple Scler.

38. Coyle PK, LaGanke C, Khatri B, et al., Improvements in patient reported outcomes with teriflunomide: week 24 interim results from the US cohort of the Teri-PRO phase 4 study, Presented at: 31st Congress of the European Committee for Research in Multiple Sclerosis (ECTRIMS), Barcelona, Spain, 7-10 October 2015, P562.

39. Radue. E-W, Sprenger T, Gaetano L, et al., Teriflunomide slows brain volume loss in relapsing MS: a SIENA analysis of the TEMSO MRI dataset, Neurology, 2016;86:Suppl. P3.089.

40. Comi G, Freedman MS, Kappos L, et al., Effect of teriflunomide on lymphocyte and neutrophil counts: pooled analyses from four placebo-controlled studies, Presented at: Joint ECTRIMSACTRIMS Meeting, Boston, MA, USA, 10-13 September 2014 P060.

41. Comi G, Freedman MS, Kappos L, et al., Pooled safety and tolerability data from four placebo-controlled teriflunomide studies and extensions, Mult Scler Relat Disord 2016;5:97-104

42. Leist TP, Freedman M, Kappos L, et al., Pooled safety analyses from teriflunomide clinical studies, Neurology, 2015;84:Suppl. P7.268.

43. Singer B, Comi G, Miller A, et al., Teriflunomide Treatment Is Not Associated with Increased Risk of Infections: Pooled Data from the Teriflunomide Development Program, Neurology, 2014;82:Supple P2.194.

44. Kremenchutzky M, Freedman M, Bar-Or A, et al., 12-year clinical efficacy and safety data for teriflunomide: results from a Phase 2 extension study, Presented at: American Academy of Neurology (ANN) 67th Annual Meeting, Vancouver, BC, Canada, Neurology (ANN) 67th

45. Bar-Or A, Freedman MS, Kremenchutzky M, et al., Teriflunomide effect on immune response to influenza vaccine in patients with multiple sclerosis, Neurology, 2013;81:552-8.

46. European Agency for the Evaluation of Medicinal Products (EMA) - Committee for Proprietary Medicinal Products (CPMP), Note for Guidance on Harmonization of Requirements for Influenza Vaccines, 1997. Available at: http://www.ema europa.eu/docs/en_GB/document_library/Scientific guideline/2009/09/WC500003945. pdf

47. Kieseier BC, Benamor M, Pregnancy outcomes following maternal and paternal exposure to teriflunomide during treatment for relapsing-remitting multiple sclerosis, Neuro Ther, 2014:3:133-8.

48. Garcia-Enguidanos A, Calle ME, Valero J, et al., Risk factors in miscarriage: a review, Eur 1 Obstet Gynecol Reprod Biol 2002;102:111-9.

49. Bar-Or A, Wiendl H, Miller B, et al., Randomized study of teriflunomide effects on immune responses to neoantigen and recall antigens, Neurol Neuroimmunol Neuroinflamm 2015;2:e70 